\title{
Study of fuel inlet temperature variations on palm biodiesel operating with a diesel engine
}

\author{
Mohd Hafizil Mat Yasin ${ }^{1, *}$, Rizalman Mamat ${ }^{2}$, Ahmad Fitri Yusop ${ }^{2}$, Mohd Hafiz $\mathrm{Ali}^{1}$ and \\ Mohamad Izuan Izzudin ${ }^{2}$ \\ ${ }^{1}$ Department of Mechanical Engineering, Politeknik Kota Kinabalu, 88450 Kota Kinabalu, Sabah, \\ Malaysia \\ ${ }^{2}$ Faculty of Mechanical Engineering, Universiti Malaysia Pahang 26600 Pekan Pahang, Malaysia
}

\begin{abstract}
Biofuel includes biodiesel is introduced to overcome the air pollution problems. Biodiesel is the sustainable and alternative fuel that derived from edible and non-edible oil produced from bio-originated species, plants, and animals. This paper presents the simulation analysis on the effect of fuel temperature variations on diesel engine performance and emission using palm-biodiesel. A one-dimensional numerical analysis, Diesel RK software is used to simulate a single cylinder, four-stroke diesel engine on the performance and emission when operated at a full load condition using fuel temperature variations ranging $300 \mathrm{~K}$ to $333 \mathrm{~K}$. Results showed that simulated results for brake power and brake torque were $0.7 \%$ each when compared to the highest and lowest fuel temperature ranging from $333 \mathrm{~K}$ to $300 \mathrm{~K}$. Moreover, higher fuel temperature for palm biodiesel tends to produce lower exhaust gas temperature and brake specific fuel consumption at a constant engine speed of $2400 \mathrm{rpm}$. It can be concluded that from the study, fuel temperature variations of biodiesel could produce a significant effect regarding engine performance and emission that influence the driving economy of the engine.
\end{abstract}

\section{Introduction}

Biodiesel is a substitute fuel that derived from edible and non-edible oils of bio-originated feedstocks through the transesterification process. Each fuel possesses its physicochemical properties that can be used to identify the fuel type. In general, biodiesel has comprised all types of fatty acid methyl esters (FAMEs) originated from different sustainable biofeedstocks, chemically produced using the transesterification process with methanol as a chemical catalyst [1]. The transesterification process is the most credible method in biodiesel production which requires an alkaline liquid catalyst, usually sodium or potassium methoxide for the chemical reaction between triglycerides and alcohol. Biodiesel and glycerol formation during transesterification process is the result of the chemical reaction between an alcohol and fatty acids [2]. In general, most of the edible and nonedible oils from various bio-feedstocks are qualified to be transesterified into biodiesel fuel [3]. Biodiesel apparently has similar composition and characteristics include Cetane

\footnotetext{
*Corresponding author: hafizil@polikk.edu.my
} 
number, energy content, phase change, density and viscosity as compared to fossilized fuel [4 - 5]. Moreover, edible oils include vegetable oils are practical to be used in common diesel engines without any functional problems when several methods are adopted in reducing their high density and viscosity including petrol-diesel, pyrolysis, microemulsification (co-solvent blending) and transesterification.

Biodiesel feedstocks comprise edible and non-edible oils from sustainable biooriginated feedstocks of plants and animals. Among vegetable oils that been recognized as among most global influential vegetable oils is palm oil. This vegetable oil has been considered the suitable candidate for replacing fossilized fuel due to its higher oil yield and easily accessible. Palm oil is harvested from the oil palm tree that planted through the tropical rainforest climate regions include Indonesia, Malaysia, West Africa and other countries. Previous investigations were conducted to study the different proportion of biodiesel blends with diesel in reducing density and viscosity when operating with diesel engines $[6-8]$. Diesel engines can be fuelled directly or blended with various diesel proportions with biodiesel on some modifications or no modification at all [9 - 12]. However, the use of chemical solvents and additional processes in reducing biodiesel's density and viscosity require more cost and equipment to be involved which should need to be considered for the benefit-cost analysis. One simple method to be introduced for reducing the density and viscosity of palm biodiesel is applying the heating element approach on the biodiesel which consistently been heated at the specific temperature before entering the engine fuel pump. Many research works have been conducted previously and are still continuing on the research to determine the influence of fuel temperature in reducing density and viscosity [13].

Furthermore, higher fuel temperature contributes to the higher injection pressure, producing shorter ignition delay in the combustion process that improves cylinder pressure as well as resulting higher energy content. In consequence, there are many experimental works have been carried out investigating the influence of fuel temperature variations of a diesel engine regarding engine performance, combustion and emission characteristics operating with biodiesel. However, despite experimental works that are not feasible in terms cost, time and manpower, there are some suggested approaches including computational simulation and modelling approaches. In the present, there are three categories of diesel engine simulation models that consist, zero-dimensional models, quasidimensional models, and multi-dimensional models. Besides modelling approaches, computational simulation approach that is using specific mathematical models could be implemented economically and efficiently for evaluating and optimizing the engine design regarding the effects of fuel on diesel engines.

Diesel-RK is a multi-zone, full cycle, one-dimensional engine simulation software which has been developed by Razleytsev, Andrey Kuleshov, and others at Bauman Moscow State Technical University and is still developed until today [14 - 15]. This software is designed for simulating and optimizing thermodynamic working processes of two, and four-stroke engines consist all types of air boosting. Interestingly, this simulation is capable of determining engine performance parameters, combustion and emission prediction and optimization. It predicts fuel consumption, piston bowl shape and fuel injection profile multi parameters for advancement with enhancement in multiple fuel injection, fuel spray location and design in different models of engines.

This paper presents the simulated data of palm biodiesel when fuelling a single cylinder diesel engine in Diesel RK software. The objective of the present work is to investigate the fuel temperature variability on engine performance and emission operating with palm biodiesel. Investigated parameters in the study are included brake power, brake torque, brake specific fuel consumption (bsfc) and exhaust gas temperature regarding on the inlet fuel temperature variations. 


\section{Methodology}

Fuel chemical compositions mainly attribute to the properties of any fuel that influence the performance and emission characteristics of the engine. Palm biodiesel is a sustainable and feasible alternate fuel (a major candidate fuel in replacing mineral diesel) for diesel engines with a chemical formula of $\mathrm{CH}_{3}-\mathrm{OOR}_{\mathrm{n}}$. It is produced from the palm oil through a transesterification process with the presence of alcohol as a catalyst. Palm biodiesel is a clean burning fuel that been regulated firmly under ASTM and EN. It has a higher viscosity and density when compared to mineral diesel, which attributes to lower atomization process. However, palm biodiesel has higher oxygen content and lower sulphur content contribute to the emission reduction. Moreover, higher fuel consumption of palm biodiesel is mainly attributed to the lower heating value (LHV) of palm biodiesel that exhibited an average value of $37.08 \mathrm{MJ} / \mathrm{kg}$ that is much lower compared to that mineral diesel. Improvement in combustion process could be highly achieved with the presence of higher oxygen content, higher stoichiometric of fuel/air ratio and higher $\mathrm{C} / \mathrm{H}$ fraction ratio that leads to the reduction of black smoke and soot emissions. The high stoichiometric fuel/air ratio, higher oxygen content, and higher $\mathrm{C} / \mathrm{H}$ ratio enhance the combustion process thus the soot and smoke emission reduced [2]. The thermo-physical fuel properties of palm biodiesel compared to the mineral diesel are listed in Table 1.

Table 1. Vapour fuel properties of diesel and biodiesel.

\begin{tabular}{|l|c|c|}
\hline \multicolumn{1}{|c|}{ Vapour Fuel Properties } & Diesel & $\begin{array}{c}\text { Palm } \\
\text { Biodiesel }\end{array}$ \\
\hline Carbon Atom per Molecule & 13.5 & $18.82^{*}$ \\
\hline Hydrogen Atom per Molecule & 23.6 & $34.39^{*}$ \\
\hline Oxygen Atom per Molecule & 0 & $2^{*}$ \\
\hline Nitrogen Atom per Molecule & 0 & $0^{*}$ \\
\hline Density $\left(\mathrm{kg} / \mathrm{m}^{3}\right)$ & 830 & $852^{* *}$ \\
\hline Lower Heating Value $(\mathrm{J} / \mathrm{kg})$ & $4.32 \times 107$ & $4.61 \times 107^{* *}$ \\
\hline Min. Valid Temperature (K) & 200 & 100 \\
\hline Max. Valid Temperature (K) & 1200 & 1200 \\
\hline
\end{tabular}

In the present work, intake system, powertrain model, exhaust system, engine cylinder and valve train are simulated in a one-dimensional (1D) engine simulation software, Diesel-RK. The effect of the tested fuels, conventional diesel and palm biodiesel on the engine performance and emission characteristics were simulated. The application of a fourstroke, one-cylinder diesel engine in a one-dimensional simulation is simulated and shown in this paper. Table 1 lists the specification of the diesel engine and Figure 1 presents the computational model of the specific diesel engine. The simulation model used standard atmospheric pressure at $1 \mathrm{bar}$ and the initial atmospheric temperature of $298 \mathrm{~K}\left(25^{\circ} \mathrm{C}\right)$. Initial intake air composition is assumed to be fresh air, with $\mathrm{O}_{2}$ and $\mathrm{N}_{2}$ as the primary gases. Furthermore, the second segment of the simulated model includes the engine cylinders, fuel injection system, intake, and exhaust system. 


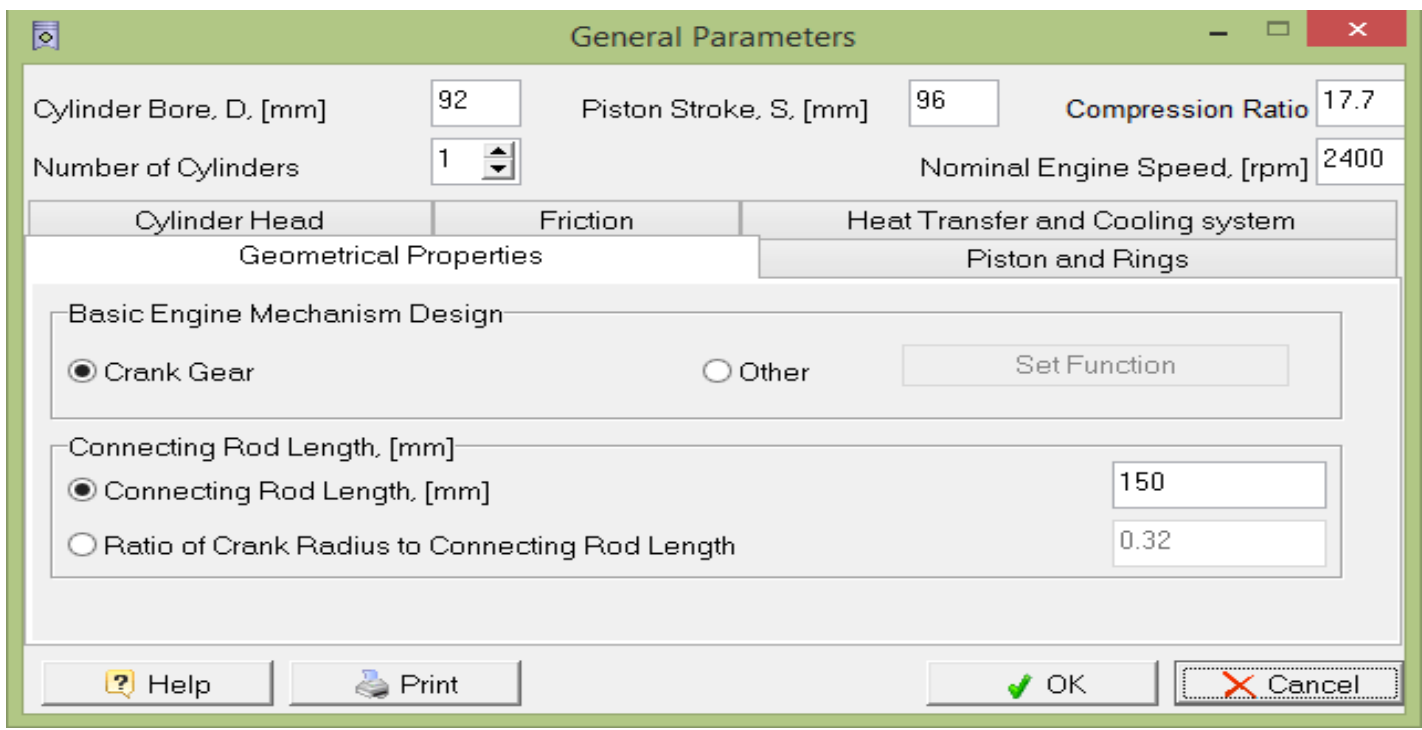

Fig. 1. A computational model of the engine [15].

Engine cylinder input parameters include the start of the cycle, cylinder geometry object, and initial state name. The start of the cycle of the engine can be defined as the crankshaft movement that represented by the crank angle and the intake valve closed. The crank angle for the engine crankshaft is 720 degree for four cycles. However, the crank angle value does not affected the simulation predictions but only specifies the starting and ending angle within one full cycle. As for the integrated and measured engine predictions, the dimensions of the bore, stroke, and connecting rod are referring to the actual engine which been mentioned in Table 2. Engine cylinder geometry data are included a bore, stroke, wrist pin to crank offset, compression ratio (CR), TDC clearance height and connecting rod length. The input for the engine simulation consists the cylinder quantity, type of cylinder arrangement and engine type. The details of the engine parameters used for the engine simulation are described in Table 2.

Table 2. Diesel engine specifications.

\begin{tabular}{|l|c|}
\hline \multicolumn{1}{|c|}{ Parameter } & Value \\
\hline Type & Horizontal, water-cooled 4-cycle diesel \\
\hline Combustion system & Direct injection \\
\hline Number of Cylinder & 1 \\
\hline Bore $(\mathrm{mm})$ & 92 \\
\hline Stroke $(\mathrm{mm})$ & 96 \\
\hline Compression ratio & 17.7 \\
\hline Displacement $(\ell)$ & 0.638 \\
\hline Connecting Rod Length $(\mathrm{mm})$ & 150 \\
\hline $\begin{array}{l}\text { Rated continuous output, hp } / \\
\text { rpm }(\mathrm{kW})\end{array}$ & $10.5 / 2400(7.8)$ \\
\hline Maximum torque, $\mathrm{kgf.m} / \mathrm{rpm}$ & $4.42 / 1800$ \\
\hline Injection timing, deg & bTDC 17.0 \\
\hline Injection pressure, $\mathrm{kg} / \mathrm{cm}^{2}$ & 200 \\
\hline $\begin{array}{l}\text { Injection hole diameter } \\
\text { number of holes }\end{array}$ & $0.26 \mathrm{x} \mathrm{4}$ \\
\hline Injection angles & $150^{\circ}$ \\
\hline
\end{tabular}


Table 3 presents the engine test condition that described the overall condition for the engine operation. There were engine parameters that used to characterize engine operation which include engine speed, load, fuel temperature variations and ambient temperature. These parameters

Table 3. Test condition.

\begin{tabular}{|l|c|}
\hline \multicolumn{1}{|c|}{ Test Parameter } & Details \\
\hline Engine speed, $\mathrm{n}$ & $2400 \mathrm{rpm}$ \\
\hline \multirow{2}{*}{ Load } & $\begin{array}{c}100 \% \text { at } 200 \\
\text { cycles }\end{array}$ \\
\hline \multirow{3}{*}{ Fuel temperature, Tf } & $27^{\circ} \mathrm{C}(300 \mathrm{~K})$ \\
\cline { 2 - 2 } & $35^{\circ} \mathrm{C}(308 \mathrm{~K})$ \\
\cline { 2 - 2 } & $40^{\circ} \mathrm{C}(313 \mathrm{~K})$ \\
\cline { 2 - 2 } & $50^{\circ} \mathrm{C}(323 \mathrm{~K})$ \\
\cline { 2 - 2 } $\begin{array}{l}\text { Naturally aspirated air temperature, } \\
\text { Tba }\end{array}$ & $30^{\circ} \mathrm{C}(333 \mathrm{~K})$ \\
\hline
\end{tabular}

\section{Results and discussion}

Engine parameters and operation were analysed to provide detailed information on engine characteristics when operated at different fuel temperature variations using palm biodiesel. The engine was simulated at different fuel temperature from $300 \mathrm{~K}$ to $333 \mathrm{~K}$ at a constant engine speed of $2400 \mathrm{rpm}$. Engine performance variations will be assessed based on the brake power, engine brake torque, exhaust gas temperature and brake specific fuel consumption (bsfc).

Figure 2 presents the effect of fuel temperature variations on engine brake power and torque variations operating with palm biodiesel and mineral diesel at a constant engine speed of $2400 \mathrm{rpm}$. Brake power is calculated when the power absorption device such as dynamometer is attached to the engine drive shaft. Higher fuel temperatures tend to produce higher injection pressure that causes lower ignition delay that resulted in an increase in brake power [16]. Shorter ignition delay causes a premature start of combustion (SOC). It is shown in the figure that palm biodiesel at higher fuel temperature $(333 \mathrm{~K})$ tends to produce higher brake power with $8.18 \mathrm{~kW}$ when compared to palm biodiesel with the lowest fuel temperature $(300 \mathrm{~K})$ which is $8.12 \mathrm{~kW}$. It is found that the difference brake power for highest and lowest fuel temperature is $0.7 \%$ at a constant engine speed of 2400 rpm. It is well understood that fuel heating value affects the engine power [17], [18]. It can be described as when the fuel temperature is decreased; the energy level is also decreased.

Engine torque for fuel temperature variations with engine speed is presented in Figure 2(b). It is found from the figure that the maximum reduction in engine torque to be achieved was $0.7 . \%$ at the engine speed of $2400 \mathrm{rpm}$ from highest to the lowest fuel temperature of palm biodiesel. Torque increases as the fuel temperature increase at a constant engine speed. This condition occurs due to the engine unavailability to consume a full charge of air at higher engine speed. Moreover, higher fuel temperature tends to produce higher fuel injection pressure at full atomization, as the fuel density is decreased. 
As a result, similar engine torques tends to be achieved when operating with two different fuels with same injection pressure.

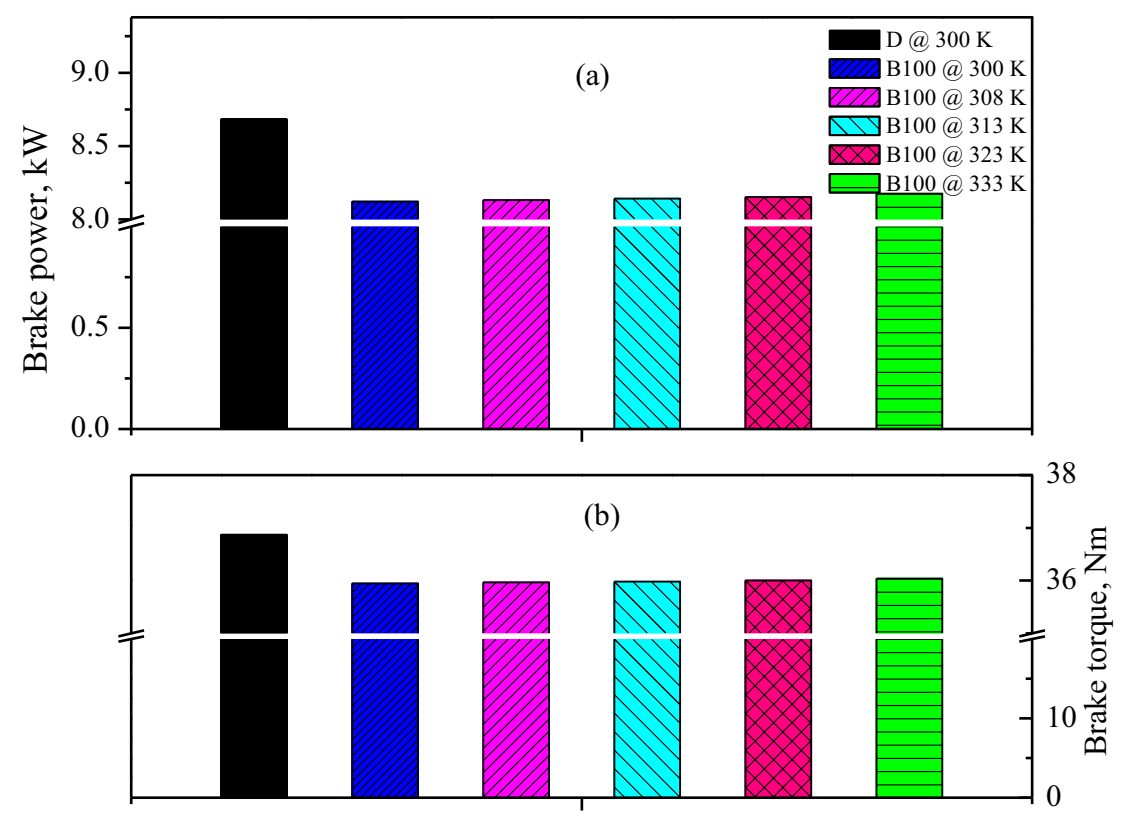

Fuel temperature variations

Fig. 2. (a) Engine brake power and (b) torque variations corresponding to the fuel temperature variations.

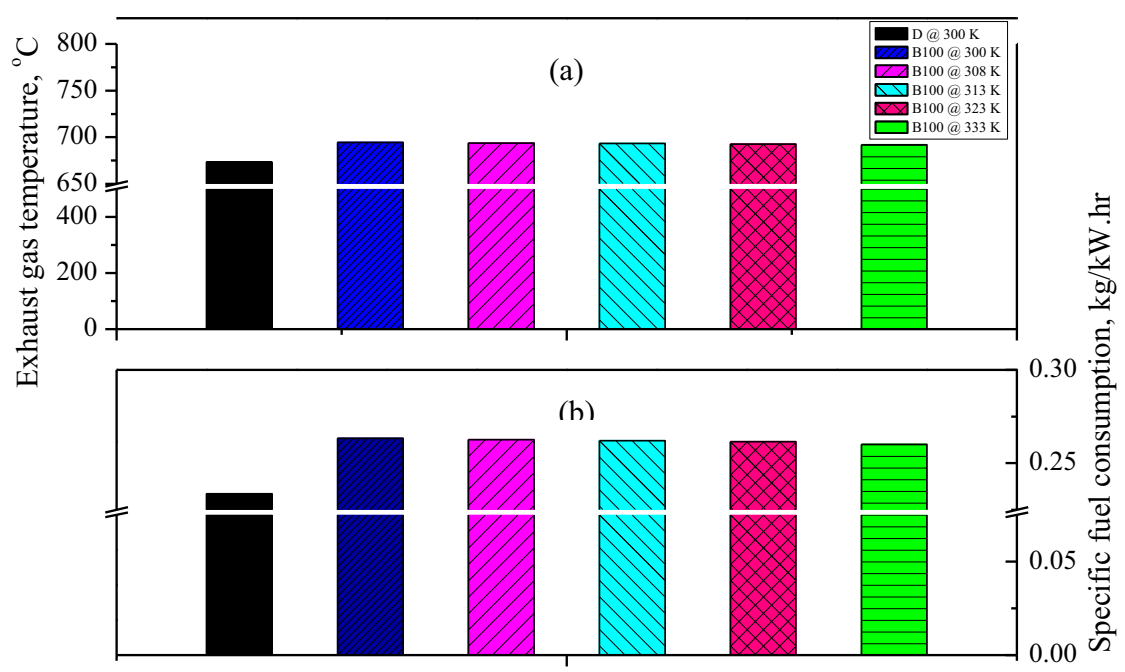

Fuel temperature variations

Fig. 3. Effect of fuel temperature variations on (a) exhaust gas temperature and (b) specific fuel consumption (sfe). 
Figure 4 shows the effects of fuel temperature variations on exhaust gas temperature and specific fuel consumption at a constant engine speed of $2400 \mathrm{rpm}$. In this Figure 3(a), it depicts variations of exhaust gas temperature that attributed from different fuel temperatures of palm biodiesel with diesel as a reference fuel. It is found from the study that palm biodiesel operating with lower temperature $(300 \mathrm{~K})$ had produced higher exhaust gas temperature at $694.6 \mathrm{~K}$ than palm biodiesel with higher temperature $(333 \mathrm{~K})$ at 691.9 $\mathrm{K}$. However, as for diesel, it produces lower exhaust gas temperature than palm biodiesel operating with different fuel temperatures. Nidal et. al. [10] and Selman et. al. [9] obtained similar results with this study.

While as for Figure 3(b), this figure shows the brake specific fuel consumption (bsfc) vary with the fuel temperature variations that corresponding to the constant engine speed. It is found that the resemblance trends for the fuel temperature variations occurred for palm biodiesel. Minimum bsfc $(0.249 \mathrm{~kg} / \mathrm{kW}-\mathrm{hr})$ for palm biodiesel was obtained at the maximum temperature of $333 \mathrm{~K}$, while the maximum bsfc $(0.251 \mathrm{~g} / \mathrm{kW}-\mathrm{hr})$ was determined at the minimum temperature of $300 \mathrm{~K}$. Lower energy content in the fuel contributes to the higher bsfe in the engine. Results clearly show that as the fuel temperature increases, the energy content as well increases, contributing lowest bsfc for the fuel temperature at $333 \mathrm{~K}$ when compared to the minimum temperature at $300 \mathrm{~K}$. Lower specific fuel consumption with better performance in torque and power are obviously most desirable with lesser emission [13].

\section{Conclusions}

The study is conducted on the effect of fuel temperature variations corresponding to the constant engine speed of $2400 \mathrm{rpm}$ operating with palm biodiesel on a single cylinder diesel engine. Following conclusions can be summarised as:

i. Higher fuel temperature contributes to the higher injection pressure, producing shorter ignition delay in the combustion process.

ii. Shorter ignition delay causes the earlier start of combustion (SOC), improving brake power and engine torque for the engine operation at a constant engine speed

iii. An increase in fuel temperature resulting higher energy content, contributing lower bsfc which is most obviously desired by any engine manufacturer

Authors are thankful to Universiti Malaysia Pahang for providing the financial support under Universiti Grant (RDU160309) for pursuing this research work at Automotive Engineering Center (AEC).

\section{References}

1. P. Adewale, M.-J. Dumont, and M. Ngadi, "Recent trends of biodiesel production from animal fat wastes and associated production techniques," Renew. Sustain. Energy Rev., 45, 574-588 (2015)

2. N. Pragya, K. K. Pandey, and P. K. Sahoo, "A review on harvesting, oil extraction and biofuels production technologies from microalgae," Renew. Sustain. Energy Rev., 24, 159-171 (2013)

3. M. M. K. Bhuiya, M. G. Rasul, M. M. K. Khan, N. Ashwath, and A. K. Azad, "Prospects of 2nd generation biodiesel as a sustainable fuel-Part: 1 selection of feedstocks, oil extraction techniques and conversion technologies," Renew. Sustain. Energy Rev., 55, 1109-1128 (2015)

4. M. H. Mat Yasin, T. Yusaf, R. Mamat, and A. Fitri Yusop, "Characterization of a diesel engine operating with a small proportion of methanol as a fuel additive in biodiesel blend," Appl. Energy, 114, 865-873.( 2014) 
5. S. Moka, M. Pande, M. Rani, R. Gakhar, M. Sharma, J. Rani, and A. N. Bhaskarwar, "Alternative fuels: An overview of current trends and scope for future," Renew. Sustain. Energy Rev., 32, 697-712 (2014)

6. S. Lahane and K. A. Subramanian, "Effect of different percentages of biodiesel-diesel blends on injection, spray, combustion, performance, and emission characteristics of a diesel engine," Fuel, 139, 537-545 (2015)

7. M. Gülüm and A. Bilgin, "Density, flash point and heating value variations of corn oil biodiesel-diesel fuel blends," Fuel Process. Technol., 134, 456-464 ( 2015)

8. A. Broatch, B. Tormos, P. Olmeda, and R. Novella, "Impact of biodiesel fuel on cold starting of automotive direct injection diesel engines," Energy, 73, 653-660 (2014)

9. S. Aydin, C. Sayin, and H. Aydin, "Investigation of the usability of biodiesel obtained from residual frying oil in a diesel engine with thermal barrier coating," Appl. Therm. Eng., 80, 212-219 (2015)

10. N. H. Abu-Hamdeh and K. A. Alnefaie, "A comparative study of almond and palm oils as two bio-diesel fuels for diesel engine in terms of emissions and performance," Fuel, 150, 318-324 (2015)

11. L. Yu, Y. Ge, J. Tan, C. He, X. Wang, H. Liu, W. Zhao, J. Guo, G. Fu, X. Feng, and $\mathrm{X}$. Wang, "Experimental investigation of the impact of biodiesel on the combustion and emission characteristics of a heavy duty diesel engine at various altitudes," Fuel, 115, 220-226 (2014)

12. C. C. Barrios, A. Domínguez-Sáez, C. Martín, and P. Álvarez, "Effects of animal fat based biodiesel on a TDI diesel engine performance, combustion characteristics and particle number and size distribution emissions," Fuel, 117, 618-623 (2014)

13. R. Rahim, R. Mamat, M. Y. Taib, and A. A. Abdullah, "Influence of Fuel Temperature on Diesel Engine Performance operating with Biodiesel Blend," J. Mech. Eng. Sci., 2, June 2012, 226-236 (2012)

14. T. Janhunen, "HCCI-Combustion in the Z Engine," SAE Tech. Pap. 2012-01-1132, pp. $1-8(2012)$

15. A. Kuleshov, "Multi-Zone DI Diesel Spray Combustion Model for Thermodynamic Simulation of Engine with PCCI and High EGR Level," SAE Int. J. Engines, 2, 1, 1811-1834 (2009)

16. A. M. Liaquat, H. H. Masjuki, M. a. Kalam, and I. M. Rizwanul Fattah, "Impact of biodiesel blend on injector deposit formation," Energy, 72, 813-823 (2014)

17. I. K. Hong, J. R. Lee, and S. B. Lee, "Fuel properties of canola oil and lard biodiesel blends: Higher heating value, oxidative stability, and kinematic viscosity," J. Ind. Eng. Chem., 22, 335-340 (2015)

18. E. Sadeghinezhad, S. N. Kazi, A. Badarudin, C. S. Oon, M. N. M. Zubir, and M. Mehrali, "A comprehensive review of bio-diesel as alternative fuel for compression ignition engines," Renew. Sustain. Energy Rev., 28, 410-424 (2013) 